\title{
Yield stress independent column buckling curves
}

\section{Stan, TudorCristian; Jönsson, Jeppe}

\section{Published in: \\ Ce/papers}

Link to article, DOI:

10.1002/cepa.432

Publication date:

2017

\section{Document Version}

Peer reviewed version

Link back to DTU Orbit

Citation (APA):

Stan, TC., \& Jönsson, J. (2017). Yield stress independent column buckling curves. Ce/papers, 1(2-3), 37613770. https://doi.org/10.1002/cepa.432

\section{General rights}

Copyright and moral rights for the publications made accessible in the public portal are retained by the authors and/or other copyright owners and it is a condition of accessing publications that users recognise and abide by the legal requirements associated with these rights.

- Users may download and print one copy of any publication from the public portal for the purpose of private study or research.

- You may not further distribute the material or use it for any profit-making activity or commercial gain

- You may freely distribute the URL identifying the publication in the public portal

If you believe that this document breaches copyright please contact us providing details, and we will remove access to the work immediately and investigate your claim 


\title{
Yield stress independent column buckling curves
}

\author{
Tudor-Cristian Stan*,a, Jeppe Jönsson ${ }^{\mathrm{b}}$ \\ ${ }^{a}$ Aqvila A/S, Denmark \\ cs@aqvila.dk \\ ${ }^{\mathrm{b}}$ Technical University of Denmark, Dept. Civil Engineering, Denmark \\ jej@byg.dtu.dk
}

\begin{abstract}
Using GMNIA and shell finite element modelling of steel columns it is ascertained that the buckling curves for given imperfections and residual stresses are not only dependent on the relative slenderness ratio and the cross section shape but also on the magnitude of the yield stress. The influence of the yield stress is to some inadequate degree taken into account in the Eurocode by specifying that steel grades of S460 and higher all belong to a common set of "raised" buckling curves. This is not satisfying as it can be shown theoretically that the current Eurocode formulation misses an epsilon factor in the definition of the normalised imperfection magnitudes. By introducing this factor it seems that the GMNIA analysis and knowledge of the independency of residual stress levels on the yield stress can be brought together and give results showing consistency between numerical modelling and a simple modified Ayrton-Perry formulation. In this paper magnitudes of imperfections and residual stresses in relation to the Eurocode will be discussed. It will be shown that the use of equivalent imperfections may be very conservative if considered by finite element analysis as described in the current Eurocode code. A suggestion is given for a slight modification of the Eurocode formulations of imperfections leading to adequate inclusion of modern high grade steels within the four bucking curves.
\end{abstract}

Keywords: column buckling, buckling curves, high strength steel, residual stress.

\section{INTRODUCTION}

This paper deals with the current formulation of the European column buckling curves, its inherent assumptions related to imperfections and yield stress and the manner in which column stability is generally treated in the context of finite element modelling. While, in recent decades, interest has indeed shifted towards lateral torsional buckling and axial force - bending moment interaction in steel members, several points still remain open regarding the benchmark column case and are addressed in this paper. A great deal of the background research regarding column stability is gathered in the ECCS 'Manual on Stability of Steel Structures' from 1976 [1], with the ECCS recommendations arriving in the form of four buckling curves two years later [2]. These buckling curves were represented by tabulated values, with no related analytical references. Subsequently, in 1978 Maquoi \& Rondal [3] gave 7 different proposals for an equivalent imperfection with which the Ayrton-Perry approach could finally be incorporated into the buckling curves. One of the proposals corresponds to the analytical column buckling curves, which have remained nearly unchanged until this day.

The equivalent imperfection which practically defines the buckling curves represents a very successful attempt of combining the negative effect of initial geometric imperfections and locked in residual stresses, while recognizing that their impact on column stability is highly dependent on the members' slenderness. With respect to actual initial geometric imperfections, there has been a general consensus since the early 70's that the assumption of an initial sinusoidal curvature with a maximum amplitude of $L / 1000$ in steel columns is perfectly justified. Most documented numerical investigations performed on columns include the initial geometric imperfection in this form. As far as residual stresses are concerned, two important points are worth noting. A self-equilibrating parabolic distribution of residual stresses for European hot-rolled members, often approximated with a linear distribution seems to fit best to experimental results and measurements, see Alpsten in 
[1]. Secondly, both the residual stress magnitude and pattern is largely independent of material properties, with the most important impact arising from the geometrical properties of the crosssection. The independence from material properties directly leads to the fact that yield stress variability does not influence residual stresses; this concept is addressed later in this paper.

The next section presents a brief overview of the assumptions for the numerical simulations used in this paper in order to establish buckling curves for columns with different imperfections, slenderness and steel grades. Subsequently, current Eurocode 3 provisions for column stability are presented, with the two main issues being identified, both from a theoretical perspective and in the context of numerical simulations. Finally, a slight modification of the equivalent imperfection formulation is proposed, which would lead to certain steel grades no longer being penalized in flexural buckling. A comprehensive historical review is given in [4], which also includes further details on finite element modelling of columns.

\section{FINITE ELEMENT MODEL}

The commercial software program ABAQUS [5] has been used for the finite element analyses. The columns with I-shaped cross-sections are modelled using general purpose S4 shell elements, with 4 nodes and 6 degrees of freedom per node. This shell element is applicable for analyses involving finite member strains and large rotations. One inherent disadvantage of using shell elements is represented by a small area of material overlap at the web-flange junctions, while the fillet radius is not accounted for; in instances in which numerical simulations are used for comprehensive reports, the accurate geometry of the cross-section can be fully reproduced with the use of beam elements at web-flange intersection points [6]. Results are presented in this paper for the IPE 160 and HEB 300 profiles with the cross-section properties used being shown in Table 1. The finite element analyses and analytical computations have been limited to strong-axis buckling, with the failure criterion used being the one recommended in Eurocode 3 part 1-5, [7], for structures susceptible to buckling, i.e. the point at which the maximum load is attained.

Table 1. Cross-section properties used in analytical calculations

\begin{tabular}{ccccc}
\hline Profile & $\mathrm{A}\left[10^{3} \mathrm{~mm}^{2}\right]$ & $\mathrm{W}_{\mathrm{el}, \mathrm{y}}\left[10^{3} \mathrm{~mm}^{3}\right]$ & $\mathrm{W}_{\mathrm{pl}, \mathrm{y}}\left[10^{3} \mathrm{~mm}^{3}\right]$ & $\mathrm{I}_{\mathrm{y}}\left[10^{6} \mathrm{~mm}^{4}\right]$ \\
\hline IPE160 & 1.98 & 107 & 121.8 & 8.56 \\
\hline HEB300 & 14.5 & 1640 & 1820 & 246 \\
\hline
\end{tabular}

\subsection{Boundary conditions and material model}

The modelled columns are considered simply supported; kinematic coupling constraints which relate the motion of groups of slave nodes to a master node are applied to nodes at the end of the member in order establish these boundary conditions and in order to ensure that all end nodes remain co-planar at all times. These constraints are shown in Fig. 1, along with the coordinate system used and the manner in which axial force is applied to the column; the main global boundary conditions and application of load are required only at the master nodes. Furthermore, these end conditions allow the free warping and 'expansion' of end sections, while flange and web nodes are constrained to remain on straight lines. Finally, since only major axis buckling is investigated in this paper, transverse deflection is restrained for web-flange junction nodes along the whole length of the member. The material model used in the present numerical simulations is the elastic-plastic bilinear model, with a strain hardening slope of E/100, as recommended in Annex C of Eurocode 3 part $1-5$, case c).

\subsection{Residual stress}

The basis for the European buckling curves and the most commonly used residual stress pattern for hot-rolled I profiles in numerical simulations is the simplified, linear model [8]. The detrimental effect on column stability is caused by compressive residual stresses which lead to premature yielding of certain parts of the cross-section; therefore, assuming same maximum levels of residual stresses, the linearized pattern is slightly more conservative than the parabolic one, since a larger 
area in the flanges have residual stresses in compression. In the present paper, this linearized pattern is used in numerical simulations, although it is worth noting that the use of this residual stress distribution may slightly underestimate buckling capacities $[4,9]$.
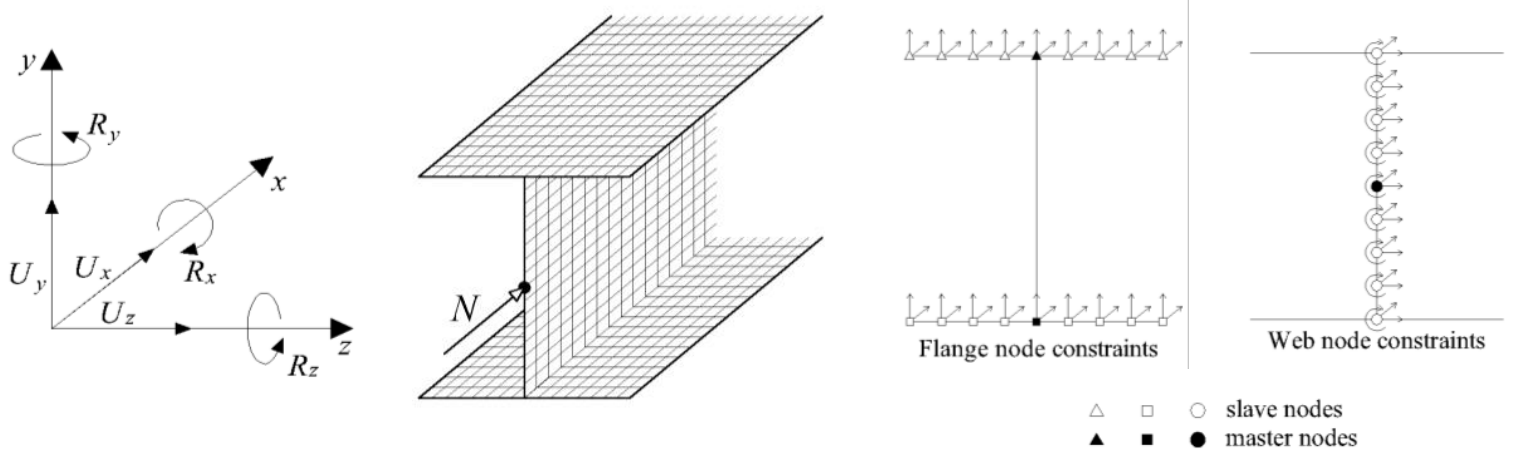

Figure 1. FE model boundary conditions.
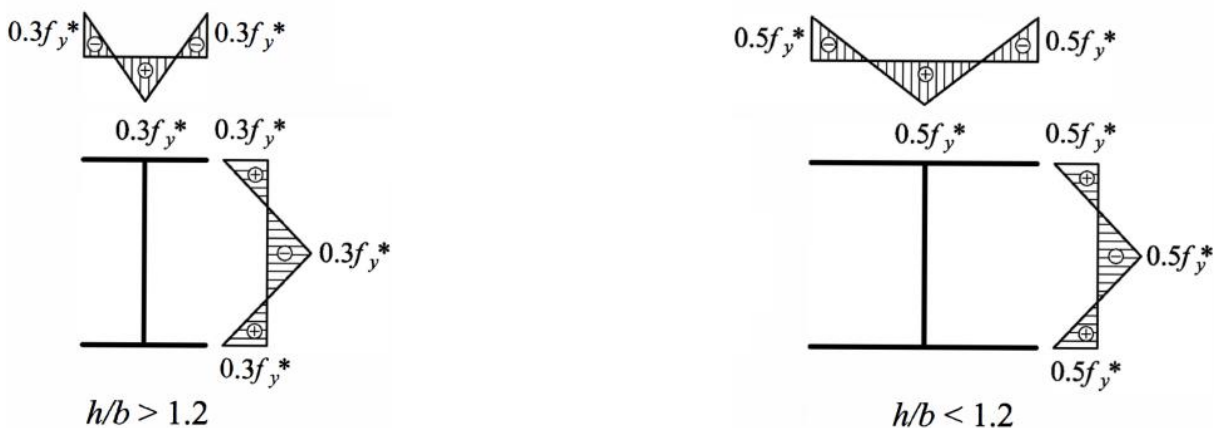

Figure 2. Residual stress patterns, where $f_{y} *=235 \mathrm{MPa}$ for non-scaled and $f_{y} *=f_{y}$ for scaled values.

The magnitude and distribution of the residual stresses are illustrated in Fig. 2. The common methodology of referring to the magnitude of residual stresses as a fraction of yield stress can unfortunately be misleading and may represent one of the reasons as to why conflicting assumptions can be found throughout the literature regarding this issue. Residual stresses are included in the numerical model through an initial thermal step, with the appropriate temperature change at any point given by

$\Delta T=-\frac{\sigma_{R}}{E \beta}$

where $\Delta T$ is the required temperature change, $\sigma_{R}$ is the intended residual stress magnitude at flange tip, $E$ is Young's modulus and $\beta$ is the temperature expansion coefficient.

The magnitude of the geometric imperfections, when accompanied by a residual stresses, is given as a maximum bow imperfection of $L / 1000$.

\section{EQUIVALENT IMPERFECTION AND BUCKLING CURVES IN EC3}

Column buckling curves are expressed through the so-called column reduction factor $\chi$, which in turn is highly dependent on the assumed expression and magnitude of the initial bow imperfection; this initial bow imperfection is considered 'equivalent', since it includes all possible effects which could lead to a reduction in capacity. The current Eurocode code seems to be 'split' between two different approaches regarding the equivalent imperfection, which, as will be shown below, lead to significantly different results. On one hand, the Ayrton-Perry type of approach primarily relates the initial imperfection to the non-dimensional slenderness of the column and leads directly to the wellknown buckling curves. On the other hand, Table 5.1 in Eurocode 3 part 1-1, [11], specifies different initial imperfection magnitudes for each buckling curve as a fraction of member length. 
There is a significant difference in equivalent imperfection magnitudes between the two approaches. Over the past decades, European specifications for magnitudes of the equivalent imperfection expressed as fractions of column length $L / \xi$ have varied to a significant degree, as shown in Table 2. The values given for the (provisional Eurocode 3) the ENV, see [10], are for weak axis buckling and they are here in Table 2 given without the influence of the safety factor influence. As for the case of major axis buckling the ENV prescribed equivalent imperfections back-calculated from the buckling curves (which is the logical direct approach). Furthermore, no clear background seems to be available regarding the choice of column length ratios assigned to each buckling curve in the current code.

Table 2. Equivalent imperfection magnitudes for plastic capacities

\begin{tabular}{ccccc}
\hline Buckling curve & Extracted from EC3 & Table 5.1 in EC3 & Table 5.5.1 in ENV & ECCS 1984 \\
\hline $\mathrm{a}$ & $\alpha_{\mathrm{a}}(\lambda-0.2) \mathrm{k}$ & $\mathrm{L} / 250$ & $\mathrm{~L} / 600$ & $\mathrm{~L} / 500$ \\
\hline $\mathrm{b}$ & $\alpha_{\mathrm{b}}(\lambda-0.2) \mathrm{k}$ & $\mathrm{L} / 200$ & $\mathrm{~L} / 380$ & $\mathrm{~L} / 250$ \\
\hline $\mathrm{c}$ & $\alpha_{\mathrm{c}}(\lambda-0.2) \mathrm{k}$ & $\mathrm{L} / 150$ & $\mathrm{~L} / 270$ & $\mathrm{~L} / 200$ \\
\hline $\mathrm{d}$ & $\alpha_{\mathrm{d}}(\lambda-0.2) \mathrm{k}$ & $\mathrm{L} / 100$ & $\mathrm{~L} / 180$ & $\mathrm{~L} / 150$ \\
\hline
\end{tabular}

The difference between equivalent imperfections back-calculated from the European buckling curves and the ones specified in Table 5.1 is shown in Fig.3a, with the former imperfection being expressed as a fraction of member length:

$\frac{L}{\xi}=\alpha(\lambda-0.2) k \Rightarrow \xi=\frac{L}{\alpha(\lambda-0.2) k}$

Fig. $3 b$ shows the analytical buckling curves obtained using these different imperfection specifications; the buckling curves obtained using the imperfections specified in the ENV have been added to the figure, in order to highlight the fact that these older imperfections result in column reduction factors which are far closer to the current, EC3 reduction factors. Fig. 4 presents GMNIA 'obtained' buckling curves for the IPE160 and HEB300 profiles, with the steel grade used being $\mathrm{S} 235$. The figures show that the analytical buckling curves are correctly re-established when using back-calculated equivalent imperfections. More importantly, the extent to which a too large global bow imperfection results in a significant lowering of the curves is seen. The results are fully consistent with the analytically derived buckling curves shown in Fig. 3b. A possible reconciliation between expressing equivalent imperfections as fractions of member length and the equivalent imperfection included in the buckling curves may be inferred from [12]: the equivalent imperfection may be extracted from each buckling curve at a relative slenderness of $\lambda=1$ and expressed in the $L / \xi$ format using $E q$. (2). However, this would still lead to a lack of consistency as the plateau before $\lambda$ $=0.2$ will not be reproduced.

\section{YIELD STRESS INFLUENCE}

The equivalent imperfection which forms the basis of the current buckling curves is dependent on the non-dimensional slenderness and thus dependent on material yield stress, as follows:

$\chi=\frac{1}{\phi+\sqrt{\phi^{2}-\lambda^{2}}}$ where $\phi=\frac{1}{2}\left(\lambda^{2}+\frac{e}{k}+1\right)$ and $k=\frac{W}{A}$

where the kernel radius $k$ is given by the section area $A$ and the appropriate section modulus $W$. The relative slenderness is depends on yield stress and the buckling stress:

$\lambda=\sqrt{\frac{f_{y}}{\sigma_{c r}}}$ where $\sigma_{c r}=\frac{\pi^{2} E i}{L^{2}}$ and $i=\sqrt{\frac{I}{A}}$

In which we have introduced $E$ as Young's modulus, $i$ as the radius of inertia and $I$ as the second

(C) Ernst \& Sohn Verlag für Architektur und technische Wissenschaften GmbH \& Co. KG, Berlin · CE/papers (2017) 

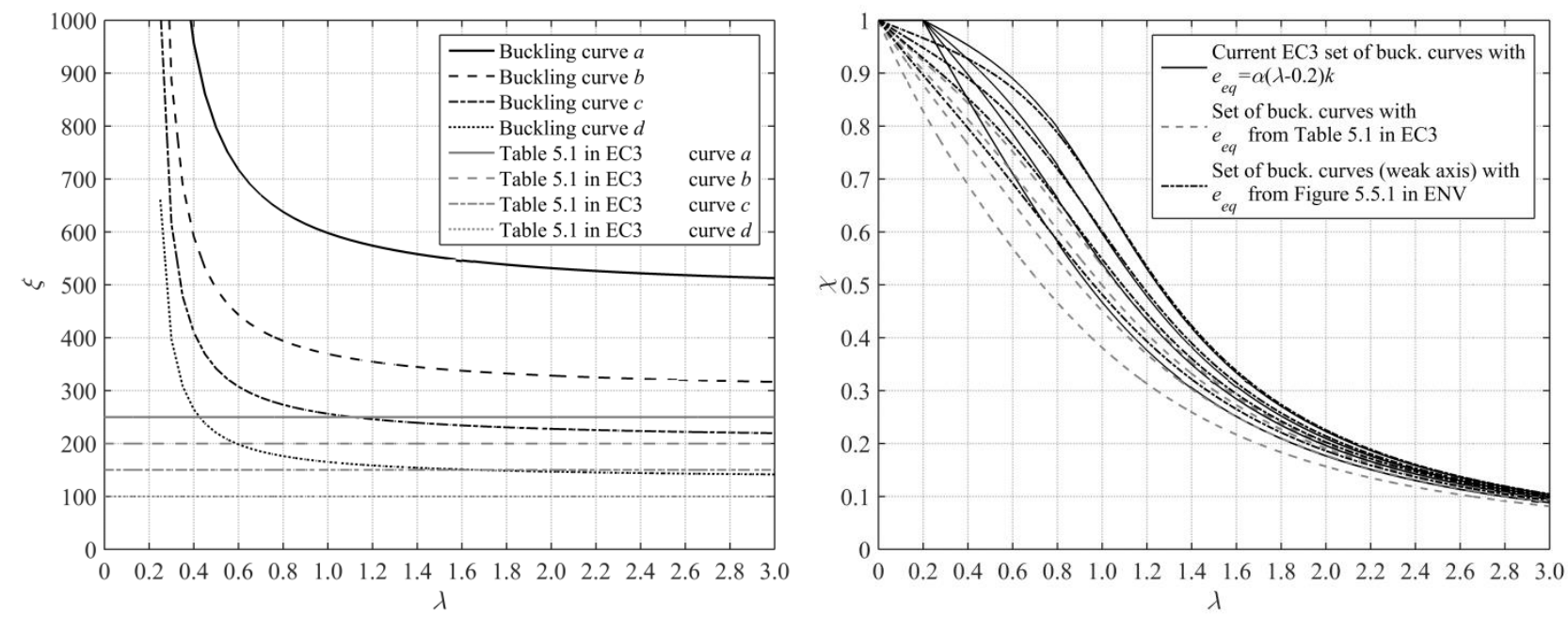

Figure 3. a) Equivalent imperfections in Table 5.1 and inherent to the buckling curves;

b) Analytical buckling curves based on different equivalent imperfections.
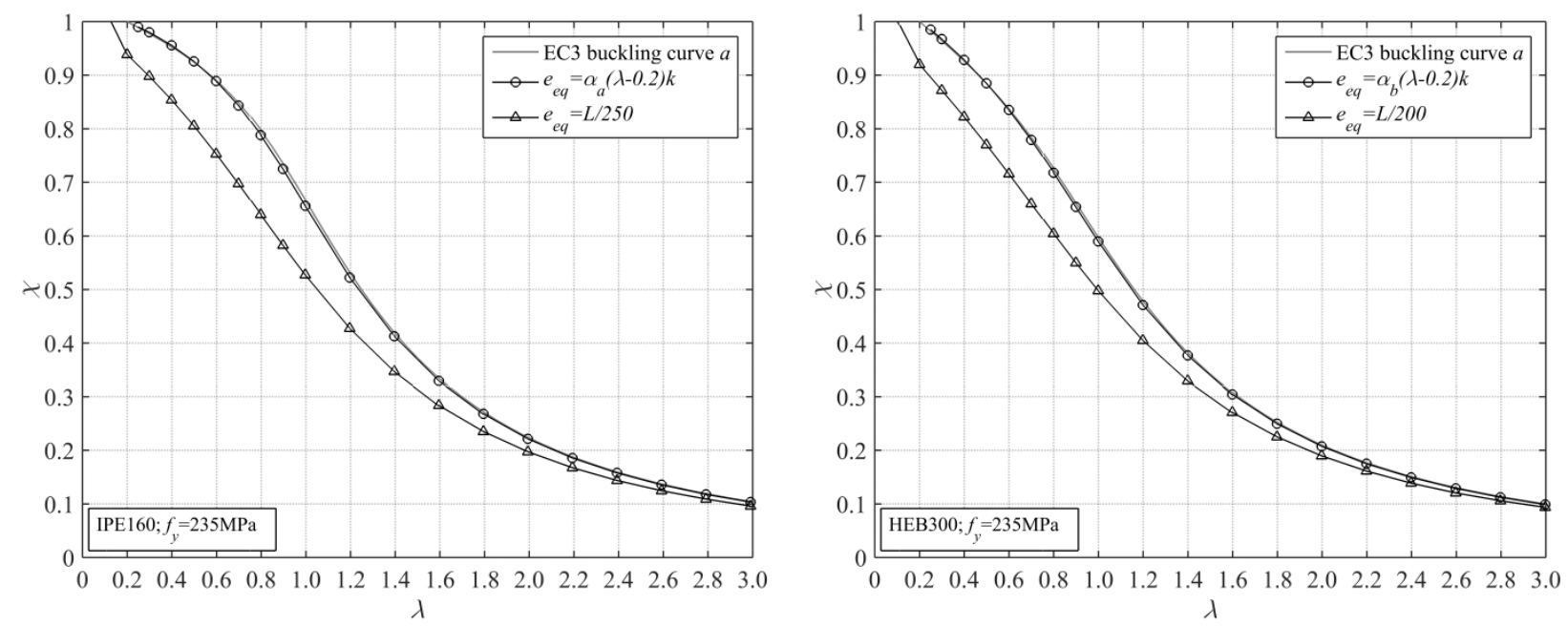

Figure 4. GMNIA results with the two equivalent imperfections.

moment of area corresponding to the axis of bending. The relation between buckling length and normalized slenderness follows:

$\lambda=\frac{L}{\pi i} \sqrt{\frac{f_{y}}{E}} \quad \Leftrightarrow \quad L=\pi i \sqrt{\frac{E}{f_{y}}} \lambda$

Bow imperfections have been historically expressed as fractions of column length $L / \xi$, where most commonly $\xi=1000$ for purely geometric initial imperfections and $\xi$ takes lower values when the imperfection considered is equivalent, i.e. residual stresses are also accounted for. Therefore, the normalized imperfection can be expressed as

$\frac{e}{k}=\frac{L / \xi}{k}=\frac{\pi i}{\xi k} \sqrt{\frac{E}{f_{y}}} \lambda=\alpha \varepsilon \lambda$

where the imperfection coefficient $\alpha$ and material factor $\varepsilon$ are given by

$\alpha=\frac{\pi}{\xi} \frac{i}{k} \sqrt{\frac{E}{235 M P a}}$ and $\varepsilon=\sqrt{\frac{235 \mathrm{MPa}}{f_{y}}}$

In the Eurocode Eq. (6) is modified by introducing the plateau and neglecting the influence of the material factor so that the normalized imperfection takes the form: 
$\frac{e}{k}=\alpha(\lambda-0.2)$

In which $\alpha$ is given by the EC3 dependent on cross-section type and on whether the yield stress is below that of S420 grade steel or not. It is important to note that, based on the assumptions that the member initial imperfections are dependent on cross-section properties and column length, Eq. (6) is the theoretical format, in which the square root dependency of the equivalent imperfection on material yield stress is removed through the material parameter $\varepsilon$. The actual format of the equivalent imperfection which forms the basis of the buckling curves in the Eurocode is given in Eq. (8), where the plateau for stocky members has been introduced and the material parameter has been omitted; this deliberate omission is attributed to 'simplicity reasons' in the recent Consistency report. [12]. For hot-rolled profiles susceptible to buckling about the minor axis, the choice between buckling curves, based on the material yield stress is presented in Table 6.2 in EC3: all steel grades up to and including S420 are assigned to the same buckling curve, while higher steel grades 'jump' one curve [11]. It is important to note at this point that the main reason for assigning different buckling curves for lower and higher steel grades is the same as the differentiation between crosssections at a $h / b$ ratio of 1.2: the influence and magnitude of residual stresses [1]. The general consensus since the 60's has been that the magnitude of residual stresses is largely independent from the material yield stress; thus, the higher the steel grade, the lower the negative influence of residual stresses. Most available numerical simulations for flexural and lateral torsional buckling, see for example [9], which include a residual stress pattern are performed on the standard grade S235 steel, with the maximum magnitude of compressive residual stress at flange tips being defined as a fraction (usually 0.3 or 0.5 ) of yield stress. In most cases, it is not clear if this assumption is related to the actual material yield stress or to a standard reference yield stress of $235 \mathrm{MPa}$. This may represent one of the reasons why conflicting assumptions can be found throughout the literature regarding the issue of residual stress proportionality with material yield stress.

Due to the fact that yield stress is inherently related to the pattern and magnitude of residual stresses in the context of member stability, GMNIA results are first given below in order to show the nonnegligible difference between two sets of basic assumptions. Fig. $5 a$ shows the natural increase in buckling capacity if the magnitude of residual stresses is not considered to scale with material yield stress. In Fig. 5b, the deviation between the two assumptions is shown for each steel grade. In both cases the differences are larger for the HEB300 section due to the larger relative magnitude of residual stresses and the well-known sensitivity to imperfections around a non-dimensional slenderness of one is seen.

The numerical simulations results presented in Fig. 6 show the gradual increase in capacity as material yield stress increases. Simulated curves are shown only for the standard S235 steel grade and S420 and S700. This is due to the fact that these steel grades represent the 'upper bounds' of the two groups of steel grades given in Table 6.2 in EC3, with the jump to the higher, a 0 buckling curve being performed at S460. Assigning one unique buckling curve to multiple steel grades directly implies that the 'upper bound' of the group will be the most penalized.

GMNIA results presented in Fig. 7 reinforce the point made in the previous section, with the addition of higher steel grades and also show the raise of the simulated curves with the increase in yield stress, when assuming equivalent imperfections as given in Table 5.1 in EC3.

As mentioned in the Introduction, it was remarked by Dwight as early as 1975 that there is no reason for multiple steel grades to be placed on the same buckling curve. From a theoretical perspective, due to the fact that the current equivalent imperfection is proportional (through $\lambda$ ) to yield stress, higher strength steel members are assumed to contain a larger initial bow imperfection and / or higher residual stresses. This is not only unrealistic, but one would expect the trend to be quite the opposite, as the manufacturing process for high-strength would be more tightly controlled.

\section{PROPOSAL OF MODIFIED EQUIVALENT IMPERFECTION}

It has been shown in the previous section that the equivalent imperfection's square root dependency and the placement of several steel grades on the same buckling curve leads to the penalization of.

(C) Ernst \& Sohn Verlag für Architektur und technische Wissenschaften GmbH \& Co. KG, Berlin · CE/papers (2017) 

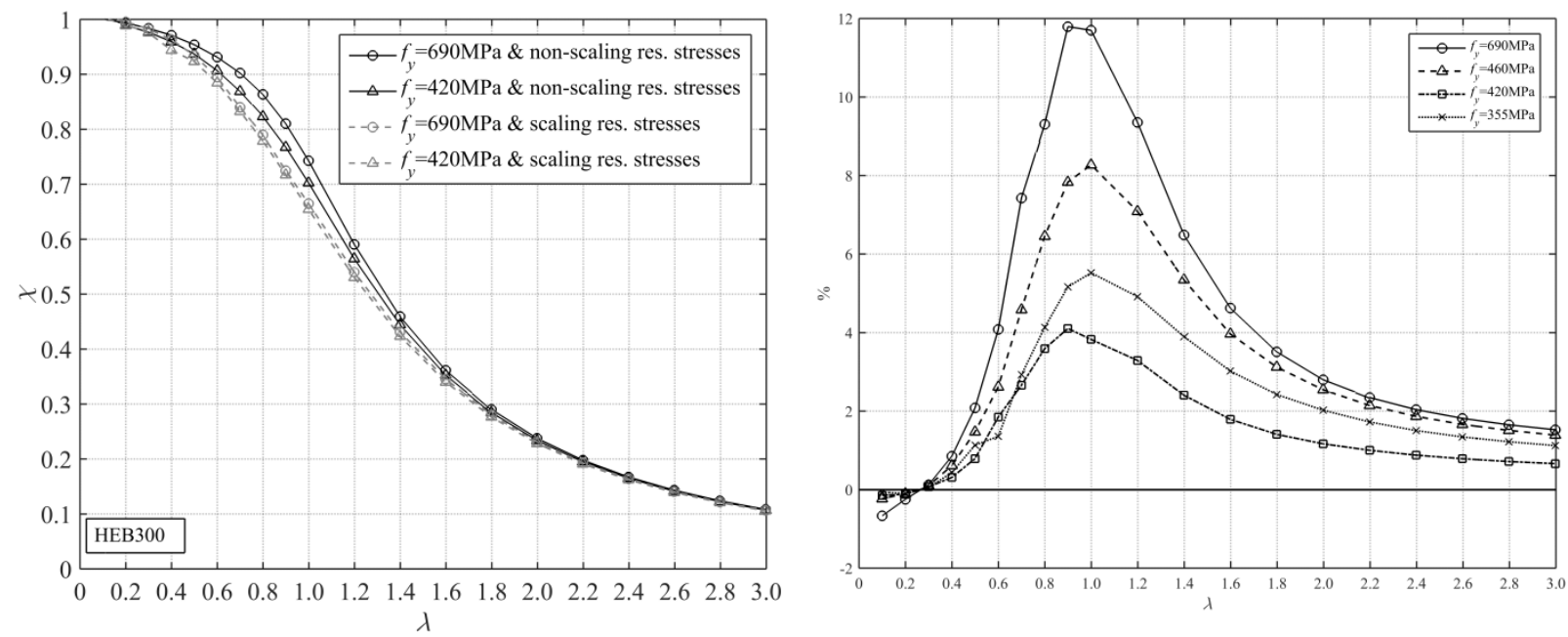

Figure 5. GMNIA results for different steel grades and residual stress magnitude a) Simulated buckling curves; b) Relative deviation between the two assumptions for each steel grade.
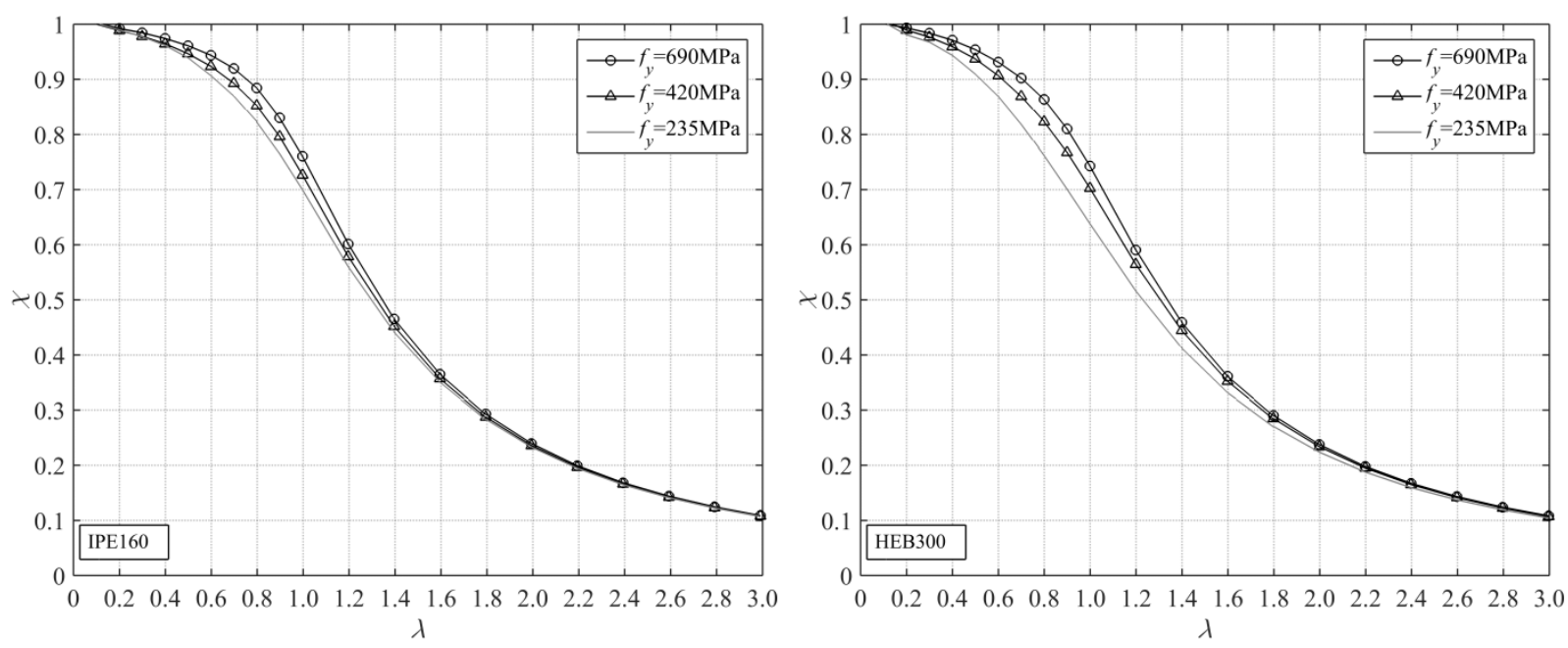

Figure 6. GMNIA results for different steel grades (L/1000 and a linear residual stress distribution).
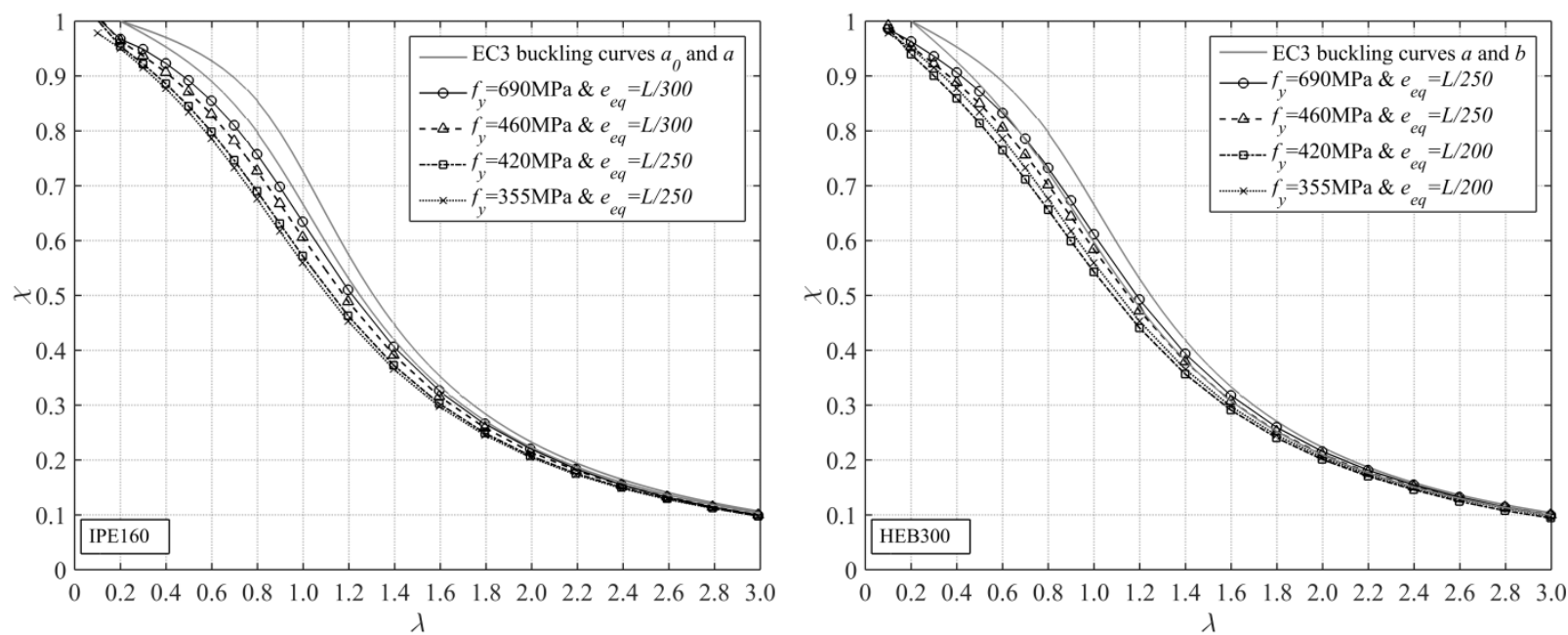

Figure 7. GMNIA results for different steel grades using Table 5.1 equivalent imperfections. 
higher strength steels. The introduction of the $a_{0}$ buckling curve only partly overcomes this issue With continuity becoming an increasing focus in European standards in recent decades and with the use of high-strength steels increasing considerably since the 70's, it is suggested that the expression of the equivalent imperfection used in the buckling curves become dependent on the slenderness $L / i$, instead of the relative slenderness, through the introduction of the well-known material parameter $\varepsilon$, as shown in $E q$. (6), but including a plateau as follows (Note the introduction of material parameter $\varepsilon$, see $E q$. (7) ):

$e_{e q}=\alpha(\lambda \varepsilon-0.2) k=\alpha\left(\frac{L}{i} \sqrt{\frac{235 \mathrm{MPa}}{\pi^{2} E}}-0.2\right) k$

A similar proposal was made by Maquoi in 1982 [13], which included the expression $\varepsilon=\left(235 \mathrm{MPa} / f_{y}\right)^{0.8}$ for the material factor $\varepsilon$, together with slightly modified imperfection factors $\alpha$. The proposal made in this paper does not change resulting buckling reduction factors for the standard S235 steel grade and thus, imperfection factors should require no modifications.
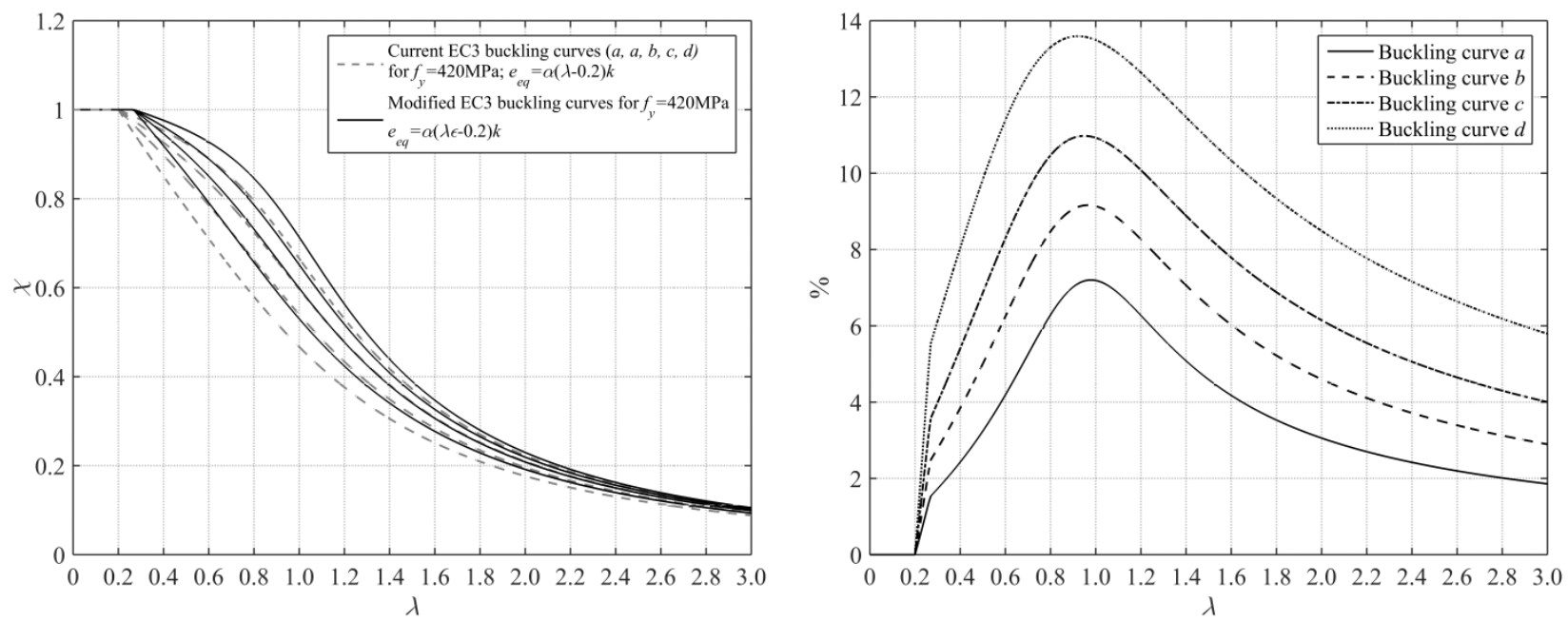

Figure 8. a) Analytical buckling curves for S420 using the proposed expression for the equivalent imperfection; b) Relative deviation between the proposal and current EC3 specifications.

The current proposal would lead to the automatic raise of buckling curves, as yield stress is increased; the resulting modified analytical buckling curves are shown for the S420, S460 and S700 steel grades in Fig. 8, Fig. 9 and Fig. 10. On the right-hand side of the figures the percentage deviation of the modified curves from the EC3 curves is illustrated. Numerical simulation results are compared in Fig. 11 to the modified buckling curves and good agreement is seen between GMNIA results and the analytical modified buckling curves.

The present study, has been limited to strong axis buckling of hot-rolled I profiles; as in numerous other papers, the inclusion of an initial geometric bow imperfection of $L / 1000$ and a linear distribution of residual stresses, independent of yield stress, have been considered to lead to the modelling of a realistic column. Although a new formulation has been proposed, investigations should be performed in order to confirm this holds true for other cross-section shapes and weak axis buckling.

\section{CONCLUSION}

It has been shown in the present paper that the current Eurocode 3 recommendations for equivalent imperfections are inconsistent with the well-known column buckling curves and lead to overly conservative results. Furthermore, the equivalent imperfection formulation which represents the basis of the buckling curves incorrectly increases the imperfection magnitude based on material yield stress, due to its direct dependence on the non-dimensional slenderness. As residual stresses 
are mainly independent of yield stress, it has thus been proposed that the equivalent imperfection expression should include the material factor $\varepsilon$, which would lead to a uniform raise of the buckling
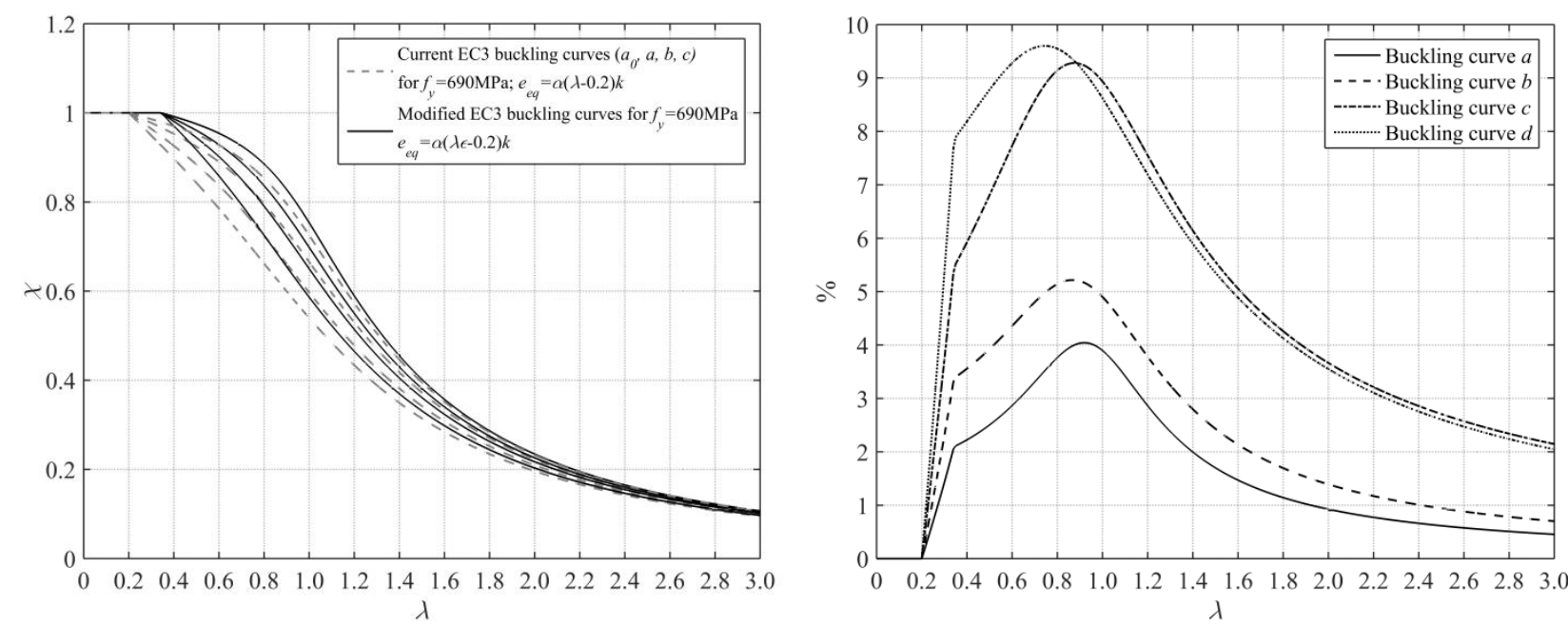

Figure 9. a) Analytical buckling curves for $\mathrm{S} 460$ using the proposed expression for the equivalent imperfection; b) Relative deviation between the proposal and current EC3 specifications.
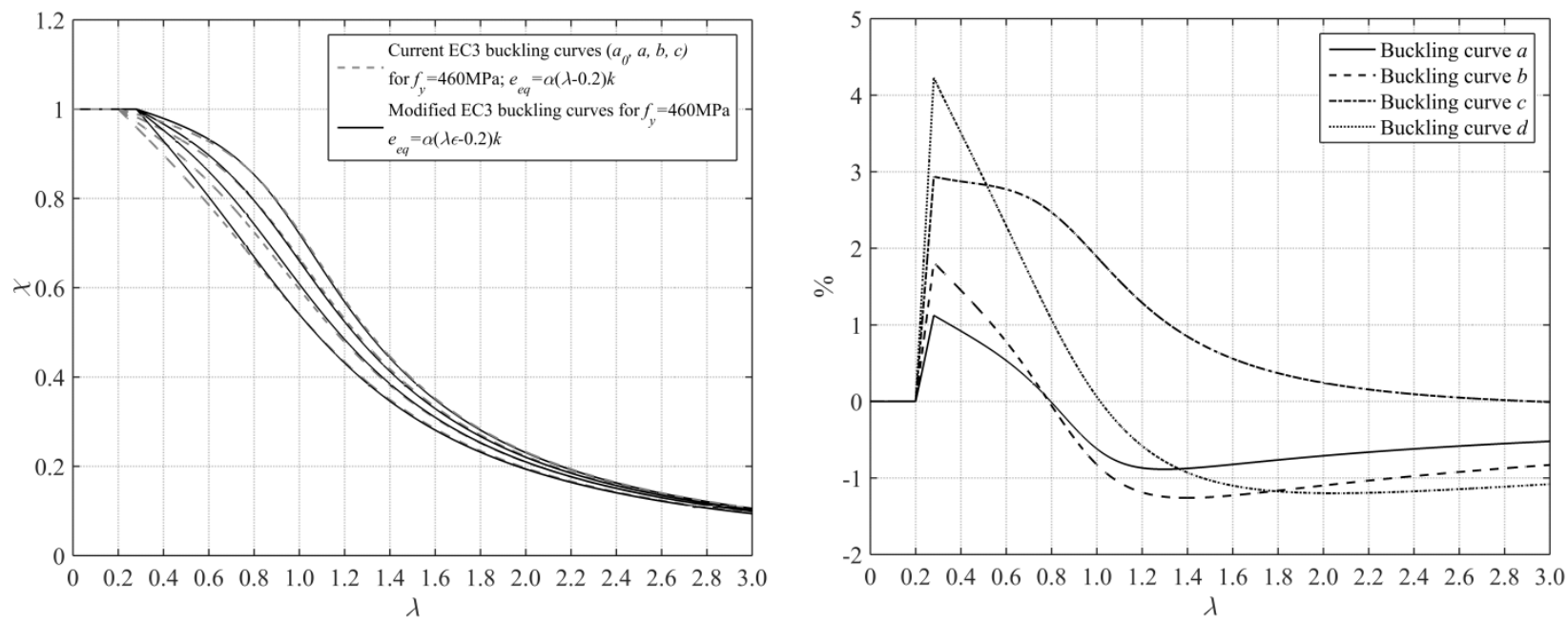

Figure 10. a) Analytical buckling curves for $\mathrm{S} 690$ using the proposed expression for the equivalent imperfection; b) Relative deviation between the proposal and current EC3 specifications
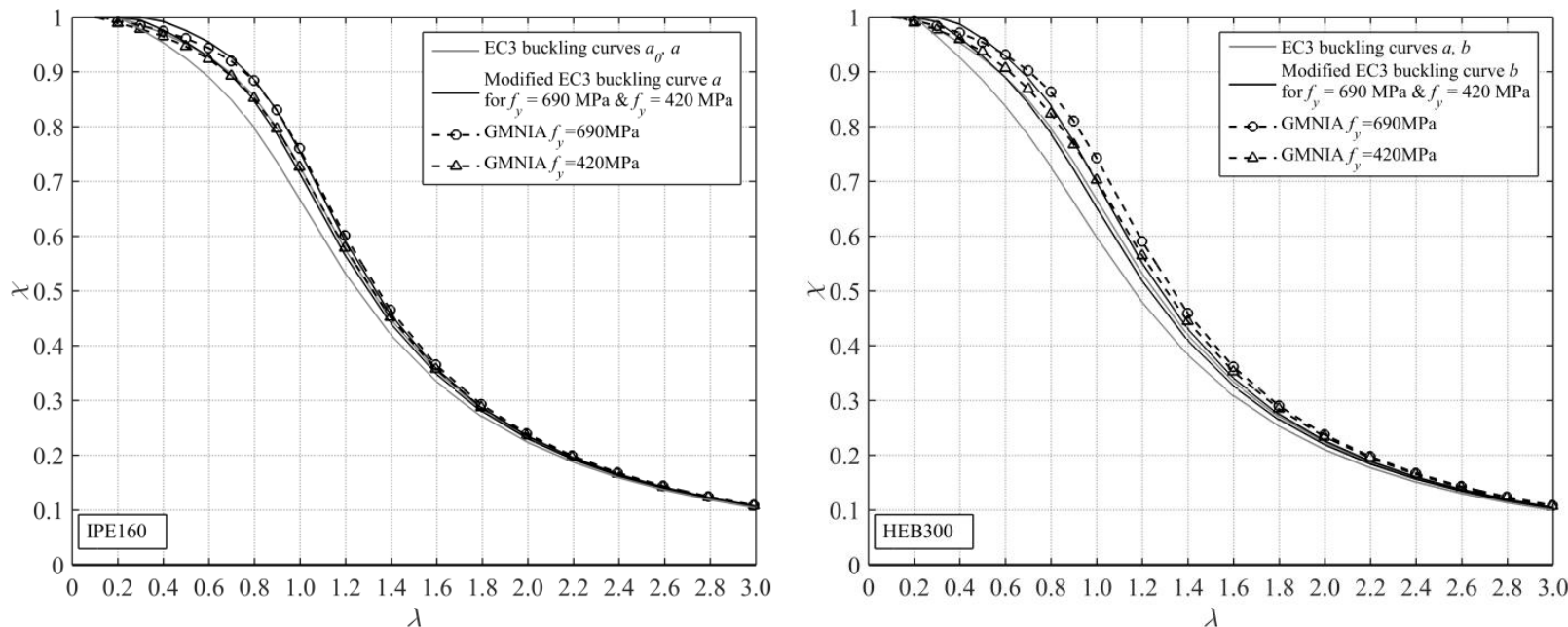

Figure 11. a) GMNIA results using $L / 1000$ and a linear residual stress distribution are compared to the analytical buckling curves obtained using the proposed equivalent imperfection.

(c) Ernst \& Sohn Verlag für Architektur und technische Wissenschaften GmbH \& Co. KG, Berlin · CE/papers (2017) 
curves, as material yield stress increases and which would no longer require an artificial 'jump' in buckling curve selection at steel grade S460. A large number of columns have been analysed through fully non-linear numerical simulations using different initial imperfections, residual stress patterns and yield stress magnitudes. The proposal for the slightly modified equivalent imperfection leads to very good agreement with GMNIA results and it would eliminate the current lack of continuity currently inherent to the buckling curves and would lead to (higher) steel grades no longer being penalized. Finally, it is worth noting that it is rather likely real column capacities could still be underestimated, as the assumption of a linear residual stress pattern seems slightly conservative and due to the fact that the assumed imperfections, which are mostly based on experimental research dating back to the 70's are outdated due to modern manufacturing processes of today's high end products.

\section{REFERENCES}

[1] ECCS 1976, "Manual on stability of steel structures", ECCS Technical Committee 8 - structural stability, 2nd ed., European Convention for Constructional Steelwork, ECCS-Publication No.22, 1976.

[2] ECCS 1978, "European recommendations for steel construction", European Convention for Constructional Steelwork, ECCS-Publication No.23, 2nd. ed, 1978.

[3] Maquoi R., Rondal J., "Mise enequation des nouvelles courbe Européennes de flambement", Construction Métallique, No 1, 1978.

[4] Jönsson J., Stan T.C., "European column buckling curves and finite element modelling including high strength steels", Journal of Constructional Steel Research, 128, 136-151, 2017,

[5] ABAQUS CAE, v6.13-4, Simulia, 2014.

[6] Greiner R., Kettler M., Lechner A., Freytag B., Linder J., Jaspart J.-P., Boissonnade N., Bortolotti E., Weynand K., Ziller C., Oerder R., "SEMI-COMP: plastic member capacity of semi-compact steel Sections - a more economic design, European Commission", Research Fund for Coal and Steel, Office for Official Publications of the European Communities, Luxembourg, 2009.

[7] EN 1993-1-5:2006, "Eurocode 3: Design of Steel Structures - Part 1.5: Plated Structural Elements", CEN - European committee for Standardization, Brussels (Belgium), 2006.

[8] ECCS 1984, "Ultimate limit state calculation of sway frameswith rigid joints", ECCS Technical Committee 8 - structural stability: technical working group 8.2 - system, European Convention for Constructional Steelwork, ECCS-Publication No.33, 1984.

[9] Boissonade N., Somja H., "Influence of imperfections in FEM modeling of lateral torsional buckling", Proceedings of the Annual Stability Confenence, SSRC - Structural Stability Research Council, Grapevine, Texas, April 18-21, 2012.

[10] ENV 1993-1-1:1992, "Eurocode 3: Design of Steel Structures - Part 1.1: General Rules and Rules for Buildings", CEN - European committee for Standardization, Brussels (Belgium), 1992.

[11] EN 1993-1-1:2005, "Eurocode 3: Design of Steel Structures - Part 1.1: General Rules and Rules for Buildings", CEN - European committee for Standardization, Brussels (Belgium), 2005.

[12] Bijlaard F., Feldmann M., Naumes J., Müller C., Sedlacek G., "Consistency of equivalent geometric imperfections used in design and the tolerances for geometric imperfections used in execution", Report CEN/TC250-CEN/TC135-Liaison, N1721, February 2010.

[13] Maquoi R., "Some improvements to the buckling design of centrally loaded columns", Structural Stability Research Council, Proceedings of the Annual Meeting, 1982. 